\title{
MASTER
}

\section{Deuterium Flow Loop for a Supersonic Gas-Target Intense Neutron Source}

by

G. Edward Cort 
In the interest of prompt distribution, this LAMS report nuas not edited by the Technical Information staff.

This work supported by the Energy Research and Development Administration, Division of Controlled Thermonuclear Research.

Printed in the Uniled Stated of America. Avcilable trom.

National Technical Infermation Serve*

U.S. Department of Commerce

5285 Port Royal Road

Price: Printed Copy $\$ 1.00$ Microtiche $\$ 2.25$

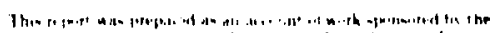

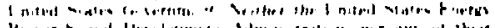

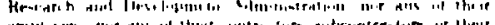

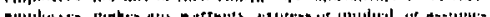

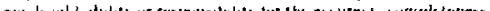

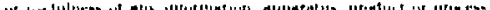

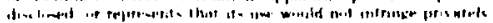

ime in it mithe 
One of the milestones to be passed in the National Controlled Thermonuclear Research (CTR) program is a thorough knowledge of the effects of high-level neutron irradiation on materials. The early needs for a highfluence $14-\mathrm{MeV}$ Intense Neutron Source (INS) to carry out such relevant studies can best be met by the supersonic gas-target approach. The INS will consist basically of two intersecting beams, one of $1.5 \mathrm{~A}$ of $270-\mathrm{keV}$ tritium ions and the other a supersonic jet of deuterium molecules. The collisional intersection of these two beams will be the source of 14-Mel neutrons from the resultant $D-T$ reaction.

Parametric calculations of inviscid one-dimensional gas dynamics and heat transfer in the deuterium fis loop (consisting of inlet plenum. target area, supersonic and subsonic diffuser sections: heat exchanger, and compressor) are described in this report. The objective was to size components and estimate operating conditions for the loop. Three parameters are relatively fixed for the lNS design being considered: 1) the kinetic energy of the tritium ion beam is $300 \mathrm{~kW}$; 2) the density of the deuterium gas in the target area (where the teams intersect) should be $2 \times 10^{19}$ molecules $/ \mathrm{cm}^{3}$ for adequate stopping power; 3) the diameter of the target area should be small $(<1.5 \mathrm{~cm})$ to maximize the neutron flux. With these limitations, and to satisfy the nonchoking condition at the exit of the target, the entering deuterium must be at high pressures (44 MPa) and stagration temperatures $(858 \mathrm{~K})$ with a Mach number of about 6 . The deuterium mass flow is $0.08 \mathrm{~kg} / \mathrm{s}$ and the stagnation temperature leaving the target area is $1375 \mathrm{~K}$. The cycle compression ratio is about 40 and the ideal compressor work is $430 \mathrm{~kW}$.

Parametric curves are given which include the sizes of components and the gas dynamic conditions throughout the deuterium loop.

The conceptual design appears to be feasible, but experimental studies are recommended to investigate effects of boundary layers in conjunction with the supersonic flow and heat addition.

\section{INTRODUCTION}

\section{A. Objectives}

Tine Los Alamos Scientific Laboratory (LASL) has proposei ${ }^{1}$ to establish a 14-MeV Intense Neutron Source (INS) for research into the effects of high-level $x$ sucron irradiation on materials. The neutrons are to be used primarily to study radiation damage phenomena similar to those anticipated in controlled Thermonuclear Research (CTR) reactor structural materials. The early needs for such a high fluence 14-MeV neutron source to carry out these relevan: studies can probably best be met by the supersonic gas-jet target approach. The INS will consist basically of two intersecting beams, one of $1.5 \mathrm{~A}$ of 270-kev tritium ions and the other a supersonic jet of deuteriun molecules. The collisional intersection (or target) of these two beams will be the sourcr: of $14-\mathrm{MeV}$ neutrons from the resultant D-T reaction. 
The innovative feature of the INS facility is development of the supersonic deuterium-gas target. operating in a vacum. Heat depositions can thereby be made several orders of magnitude higher than in comparable size solid targets, with higher neutron-source intensities the result. However, the very problem of heat deposition in the deuterium jet introduces several new problems to the flid dynanical studies in the interaction region, where the tritium-ion beam is in collision with the deuterium jet. The deuterium jet becomes tritium-contaminated at the target area. To satisfy radiological safety standards, the contaminated deuterium must be contained and the loop closed through a pressure recovery system. The primary elements in the deuterium loop (Fig. 1) axe the diffuser, heat exchanger, tritium separator, compressors, and the jet nozzle. This report describes results of parametric calculations to size components and establish flow conditions in the deuterium loop. The calculations are preliminary in nature becalse they are based on inviscid, one-dimensional, ideal gas assumptions. Detailed numerical calcuiations and experiments will be necessary to refine these estimates. The results are useful at this early stage in the program to explore feasibility, make cost estimates and programmatic plans, and direct the emphasis for the more detailed studies.

\section{B. Requirements}

Referring to Fig. 1 , the energy added in the target area, $\Delta Q$, is the kinecic energy of the tritiun ion beam. The $D-T$ reaction energy is negligibie by comparison. It is desirable to minimize both the pressure losses in the system and the size of the target area. A small target area yields a higher neutron flux for a fixed beam strength, but it also riquires high system temperatures and pressures.

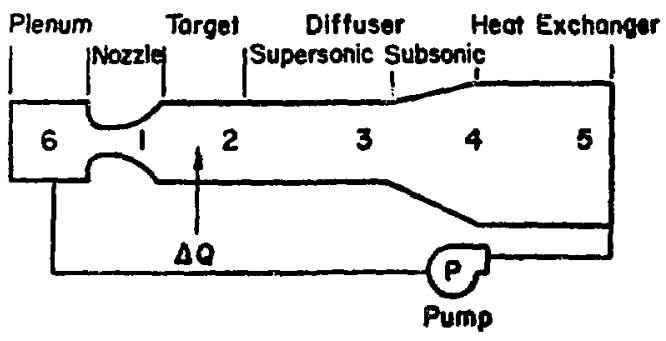

Fig. 1. Schematic of deuterium flow loop.
This will place severe requirements on structural materials in the flow loop. The deuterium density in the target area should be $2 \times 10^{19}$ molecules $/ \mathrm{cm}^{3}$ $\left(0.13 \mathrm{~kg} / \mathrm{m}^{3}\right)$ for adequate stopping power of the tritium ion beam ${ }^{l}$. The tritium beam power, $\Delta Q=300 \mathrm{~kW}$ was held fixed in these calculations while all other system variables were changed parametrically.

II. RESULTS

The discussion is divided into three parts, dealing with the deuterium expassion nozzle and interaction target area first, then the flow loop, and finally details of the heat exchanger itself.

A. Nozzie and Target Area

\section{Introduction}

The deuterium flow enters an expansion nozzle with a certain stagnation pressure $\left(P_{O_{1}}\right)$ and stagnation temperature $\left(T_{01}\right)$. The flow is expanded to supersonic velocity and immediately enters the target area where it is intersected by the tritium-ion bean (Fig. 2).

Leakage from the deuterium jet into the ionbeam tube will determine the vacuum pumping requirements. Experiments and two-dimensional flow calculations will be necessary to determine the deuterium leakage, but it will increase with increasing ratio of energy deposition to entering gas kinetic energy, $f=\frac{\Delta Q}{1 / 2 m V^{2}}$, and decrease with increasing ontering Mach number, $M_{1}$, where $t h=$ deuterium mass flow and $v=$ deucerium velocity.

\section{Maximum Energy Addition}

When the value of $\Delta Q, M_{l}$, and target gas density $\rho_{1}$ are fixed, the product of $f$ and the target

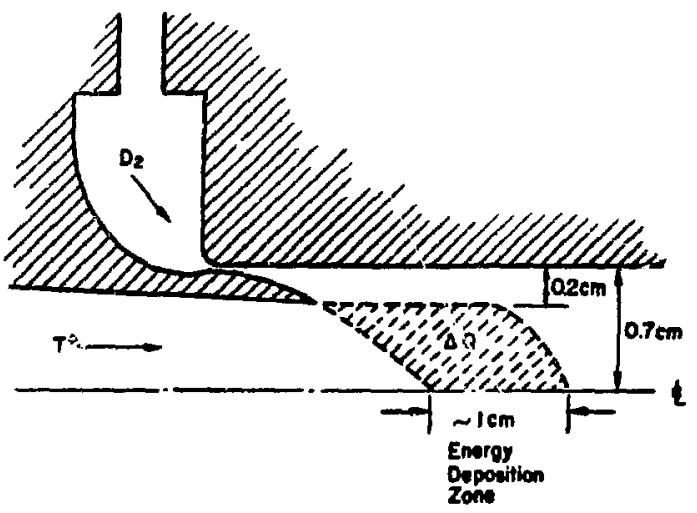

Fig. 2. Schematic of nozzle and target area. 


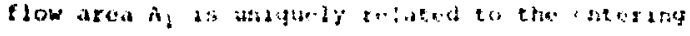

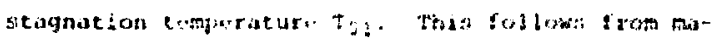

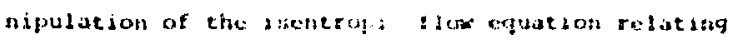

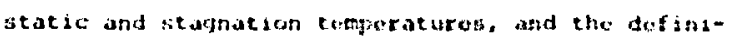
tions of $f$ and $n_{1}$. The catering beaqhataos composature must ine:sif $\gamma$ :

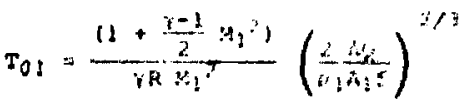

where

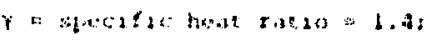

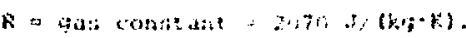

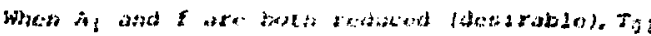

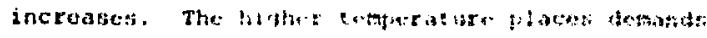

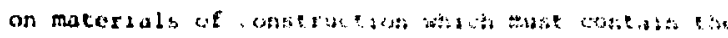

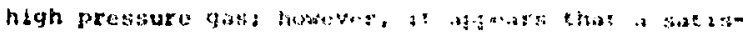

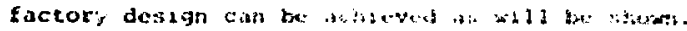

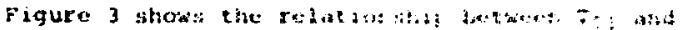

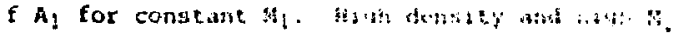

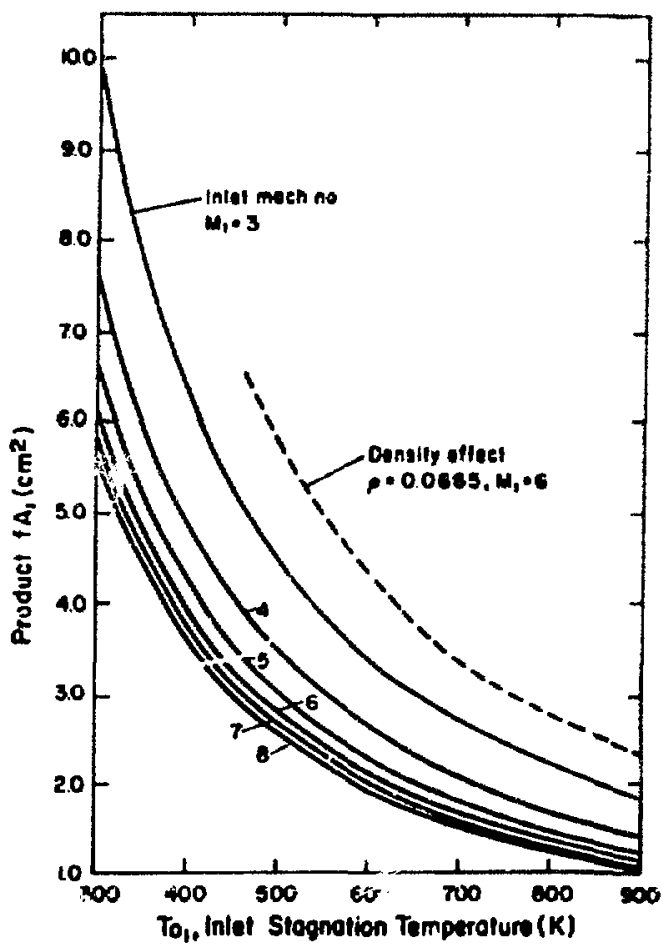

Fig. 3. Product of flow area and energy deposition fraction versus inlet stagnation tomperature.

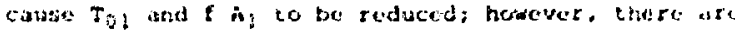

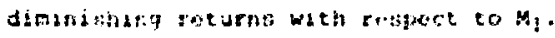

Til. chohithy phenomenon in a conetast areat duce

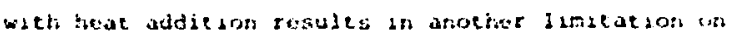

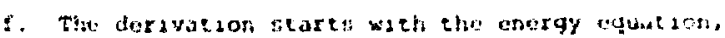

$$
\therefore t_{i}\left(\tau_{32}-T_{0}\right)
$$

wisin-2.

$$
\begin{aligned}
& \left.c_{1}=\text { atacifle neat }=72.5 \mathrm{~s} / \mathrm{kg} \cdot \mathrm{k}\right) \text {, and }
\end{aligned}
$$

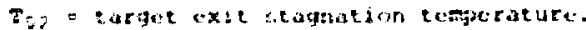

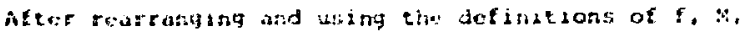

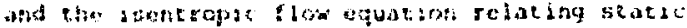

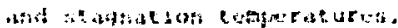

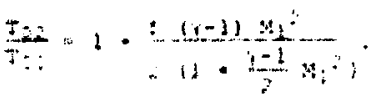

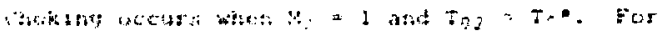

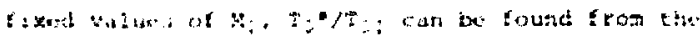

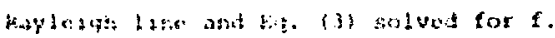

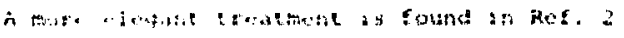

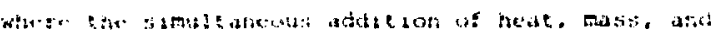

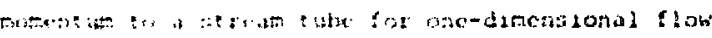

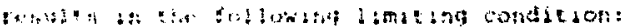

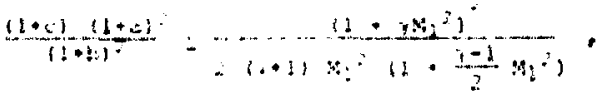

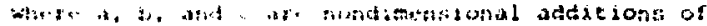

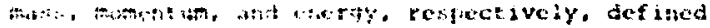

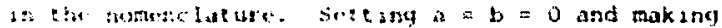

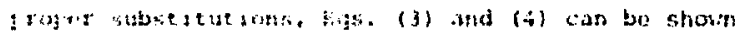

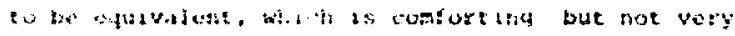

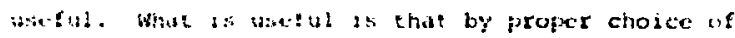

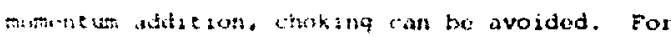

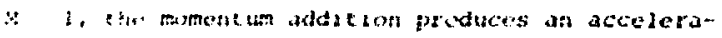

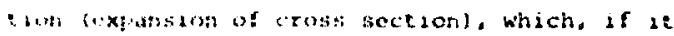
nacur:; :at: a : ate ly downstean of the high neutrot: the zone, an lake flake without a screasing $A_{1}$.

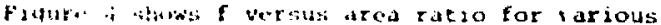

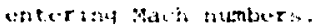

\section{Re baxat 10n T1me Stale}

The above maglects the fact that te heat addizon and pressure equalization require time. The parametre of imtortance is the ratio of the timestale of the lelaxatson, $t_{k}$, to that of the Elow. 


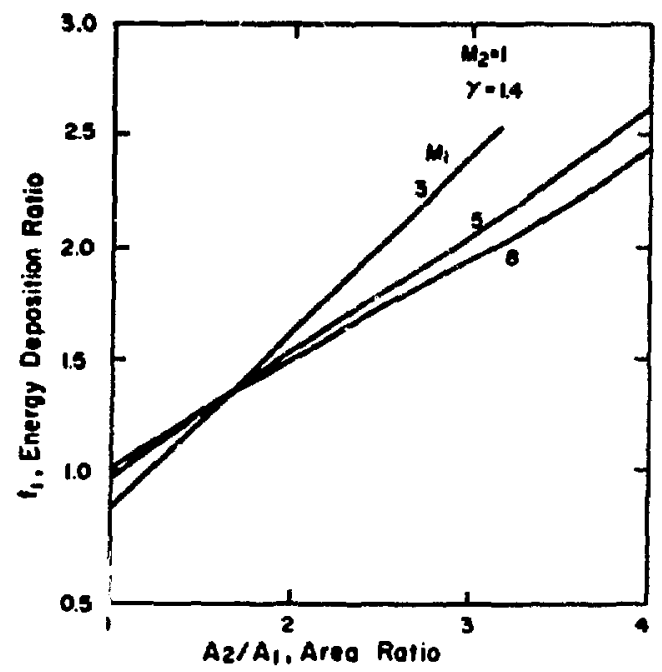

Fig. 4. Maximum energy deposition ratio in friciionless duct.

$t_{i}=2 / v_{l}$. whore $l$ is the length of interest (say $0.01 \mathrm{~m})$. This is the Lamköhlce number $D$, defined by

$D=\frac{t_{f}}{t_{R}}=\frac{2}{v_{l} t_{R}}$.

There are three relaxation times of interest: the first is the time to deposit the ion beam's kinetic spergy in the deuterium gas. If the tritiun ans are stoped la a serles of electron-ion colltsions. in with the ion energy is considerably qreater than the average electron energy, the time constant for the ion's energy to be reduced by $\frac{1}{1}$ is $t=1.1 \times 10^{12} \mathrm{Te}^{3 / 2} /$ Ne where Te is the vic. tron eneray in $\mathrm{keV}$ and $\mathrm{Na}$ is electron density. With an ionized electron dunsity of $2 \times 10^{1 \%} \mathrm{per} \mathrm{cm}^{3}$ $\left(\frac{1}{100}\right.$ the deutertum molezular density), and

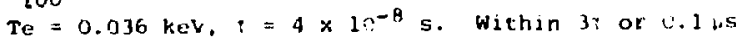
then. the lons lose 95 of their initlal kinatac anergy. Tha deuterium gas velocity is typically $3 \mathrm{~km} / \mathrm{s}$, so $c_{f}=3 \mathrm{as}$ and $\mathrm{D}-31$ ). Therefore, che heat doposition takes a short time and the flow in the turget arei inay choke.

The second relaxition time of interest is for the D-T reaction to take place. Again using Ref. S, this is estimated to be about $10 \mathrm{us}$ and $\mathrm{D}-0.3$. Since thc D-T reaction is about two orders of magnutude slower than the ion-electron collision rate, it will be difficult to enlarge the duct to accommodate potential choking. More precise calculation of the above rates will be needed before final conclusions can $t ;$ made, however.

The third relaxation time of interest is the - Iffe for ralial prossure equalization after the heat is dopowteed (concentrated at the centerline). Because the heat deposition is complex both radially and axially and because of jblique shock waves in the target area, only a rough order of magnitude estimate can be made. Assume all of the energy is deposited uniformly in a 5-mm-radius cylinder projected from the beam tube, and none is deposited in the 2-mm-thick annulus surrounding it (Fig. 2). Assume the heat is deposited instantaneously at constant valume (constant derisity) in this zone causing a radial discontinuity in pressure and temperature. Instead of looking at the Damköhler parameter, we equate the time for the gas to travel $z x i a l l y$ a cistance, $q$ of $10 \mathrm{~mm}$ with the time for the shock wave to travel radially a distance of $2 \mathrm{~mm}$. This results in a desired velocity ratio $U / V_{1} \leq 0.2$, where $U$ represents the radial velocity eitias of the shock wave or the following contact discontinuity. Using the normal shock tables as applied to a shock tube, ${ }^{4}$ Fig. 5 shows the velocity ratios versus

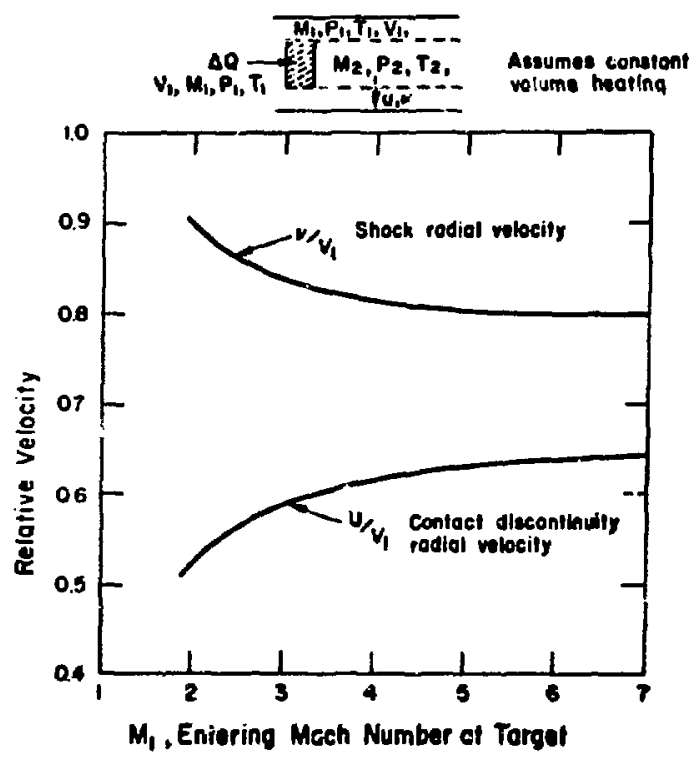

Fiq. 5. Radial velucity of idealized contact discontinuity caused by nonuniform heating. 
entering Mach numbers. The radial velocities are the naximum values, before the oressures have begun to equalize, so that time-integrated average velocity ratios will be less. Still, the pressures will equalize relatively quickly.

The relaxation phenomena have been ignored in the work which follows and the duct diameter is held constant. To avoid choking, the parametric study limits the target exit Mach number, $M_{2}>1$, and the ratio of energy deposition to entering gas kinetic energy, $f<1$.

\section{Static Pressure Recovery in Target Area}

The static pressure recovery influences design and performance of downstream components, but is hard to predict because of complex shock waves in the target area. An upper limit might result from a normal shock and a lower limit from following the Rayleigh line (no shocks). Perhaps the most realistic onedimensional estimate would result from the Hugoniot equation $^{5}$, derived from the conservation laws and valid for all types of gas dynamic discontinuity.

$h_{2}-h_{1}=1 / 2\left\langle P_{2}-P_{1}\right\rangle\left(\frac{1}{\rho_{1}}+\frac{1}{\rho_{2}}\right)$,

where $h_{2}, h_{1}$ are exit and entering enthalpies, $P_{2}$. $P_{1}$ static pressures, and $\rho_{1}, \rho_{2}$ densities. If it is asfsumed the change in gas density is small, $\rho_{2}-\rho_{1}$, rearrangement and substitution of iser.tropic relations gives:

$P_{2} / P_{1}=1+\frac{\gamma}{\gamma-1}\left(1+\frac{\gamma-1}{\because} M_{1}^{2}\right)\left(\frac{T_{02}}{T_{01}}-1\right)$.

Figure 6 compares the static pressure recovery base 1 on the three methods.

\section{B. Deuterium Flow Loop}

1. Method and Assumptions

Flow conditions around the loop sketched in Fig. I were calculated by a small computer program for fixed values of $\Delta Q, M_{l}, M_{2}$, and $D_{l}$. Inviscid, one-dimensional, ideal gas assumptions were used. The following additional assumption:s were made.

- static pressure recovery in the target area was based on either the hayleigh line or the Hugoniot equation for constant density. Figure 7 illustrates the effect of this assumption for constant inlet and exit Mach number.

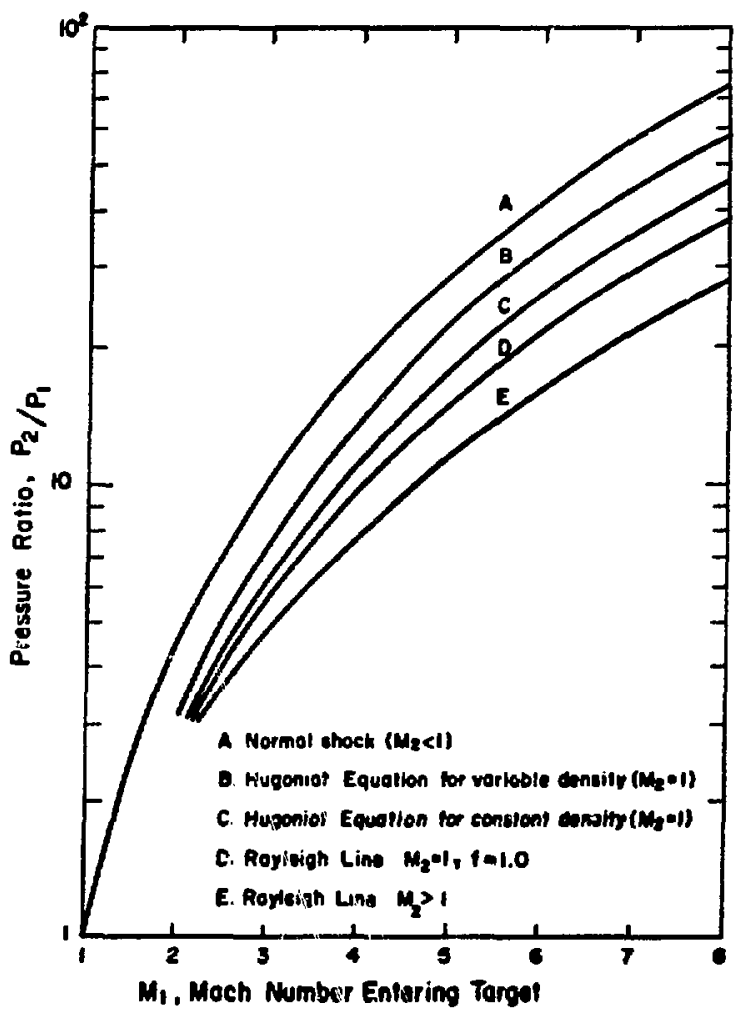

Fig. 6. Static pressure reccvery in target area.

- Static pressure recovery in the supersonic diffuser section is based on a normal shock. ${ }^{6}$ A second throat diffuser could be more eff :cient, but is not justified for low inlet Mach numbers.

- The subsonic diffuser section is sized with a $3^{\circ}$ half-angle to achieve an exit Mach number of 0.1 . Its assumed pressure efficiency is 0.8 .

- The heat exchanger is a single tube, concentric, counterflow-type with nonboiling water in the outer annulus. The gas exit temperature and water inlet and outle: temperatures remain fixed at $400 \mathrm{~K}, 290 \mathrm{~K}$, and $336 \mathrm{~K}$, respectively. The thickness of the tube separating the two flows is 10 of of the inner diameter and its thermal conductivity is $25 \mathrm{~W} /(\mathrm{m} \cdot \mathrm{K})$ stainless steel).

- $D_{2}$ pressure loss in the heat exchanger is based on turbulent flow, with the Reynolds 


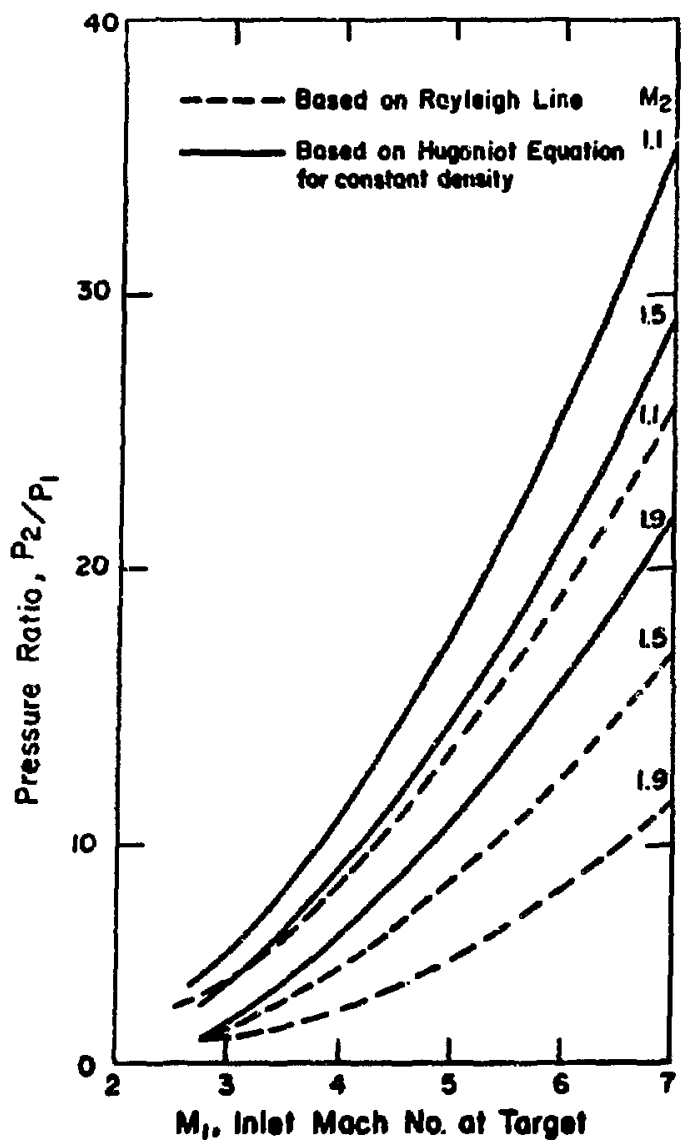

Fiq. 7. Static pressure recovery in target area.

aralogy between heat and momentum cransfer remaintng valid. This is a good assunfution for gases.

- The ideal pumping power is based on isentrop16 compression from an iniet temperature of $400 \mathrm{~K}$ and the heat exchinger exit pressure (no pressure losses for piping. vaives, or fittings).

- The stagnation inlet tomperature to the nozzle is equal to 75 s of the adiabatic compressor exit temperature to allow for unavordable cooling. This results in the desixed high inlet temperature (Fig. 3) without the need for auxiliary heating.

- The nozzle stagnation pressure is baserl on the specified tarqet inlet :tach number, density, and the temperature aloove.

\section{Results}

Figure $B$ shows the relatjonship between the inlet and exit Mach numbers and the energy deposition ratio. The energy deposition ratio is maximized when $M_{1}$ is high and $M_{2}$ approaches 1 . In the paxametric calculations, $M_{1}$ ranged from 3 to 7 and $M_{2}$ from 1.1 to 1.9. Figure 9 shows the cycle compression ratio to be sirolgly dependent on $M_{1}$ and not sensitive to $M_{2}$ for the range studied. Target inlet stagnation temperature (based on 758 of the isentropic pump outlet temperature) shows similar sensitivity to $M_{1}$ and $M_{2}$ as expected (Fig. 10). The ideal pump work is less sensitive to $M_{1}$ because of the compensating effect of the mass flow rate's decrease with increasing $\boldsymbol{H}_{1}$ (Fig. 11). Pump work increases with $M_{2}$ because mass flow increases and also because of the increased inefficiency of supersonic diffusion with higher Mach numbers (Fig. 12\}. Figure 13 shows target stagnation pressure increases rapidly beyond $M_{1}=6$. In Figure 14 , the enexgy deposition ratio, $C_{\text {. }}$ is insensitive beyond $M_{1}=6$. but is very dependent on $M_{2}$. Target area decreases with increasing $M_{1}$ and with decreasing $M_{2}$. To hold

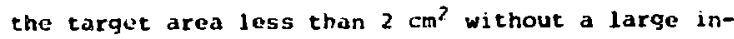
crease in juressure, requires $A_{l}-5$ and a target inlet pressure near $45 \mathrm{MPa}$ (6500 psi). The choice of $H_{2}$ involves a cradeof between $f$ and target area which must be made on the basis of two-dimensional calculations and axporiments. For $M_{I}=6$ and

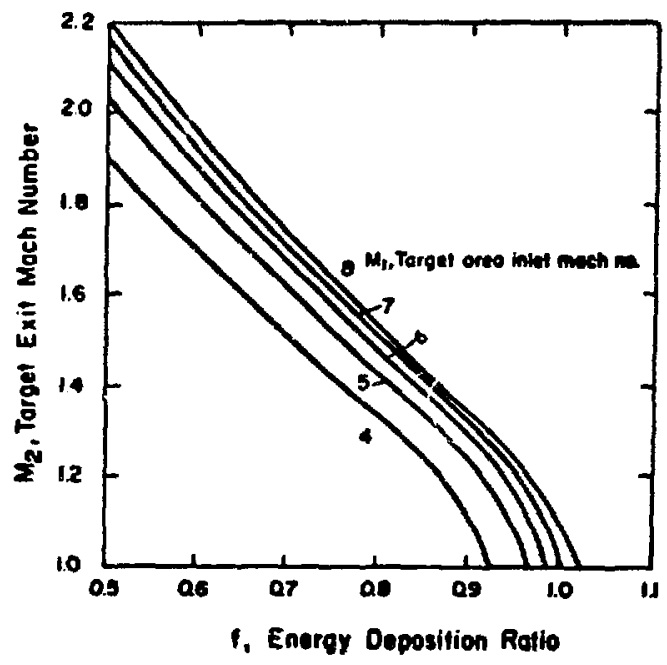

Fig. 8. Target area exit Mach number versus energy diviusition ratio. 


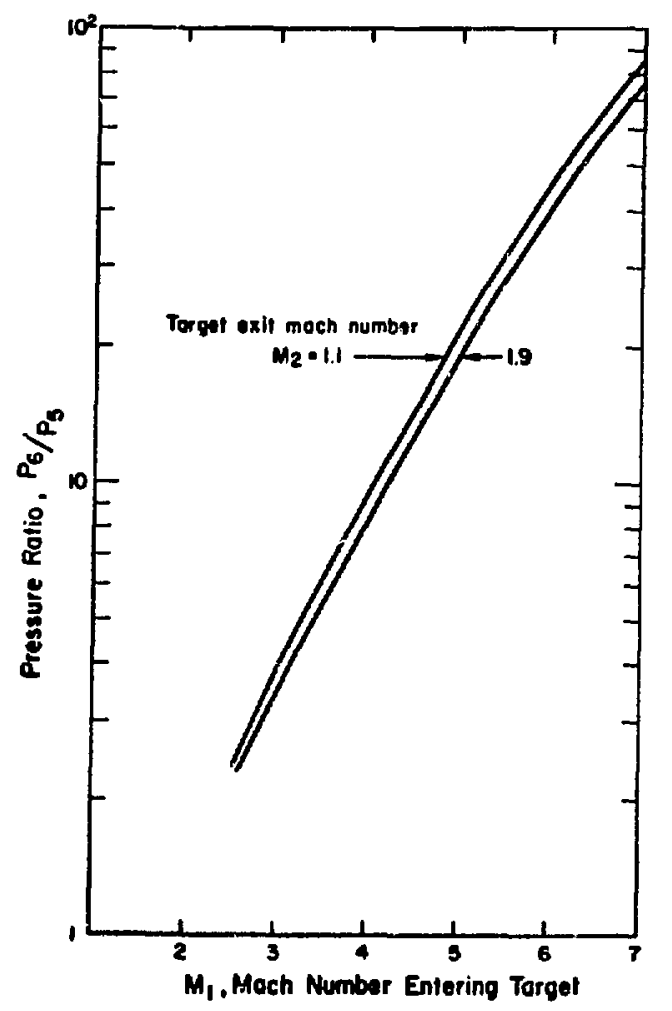

Fig. 9. Sycle compressica ratio.

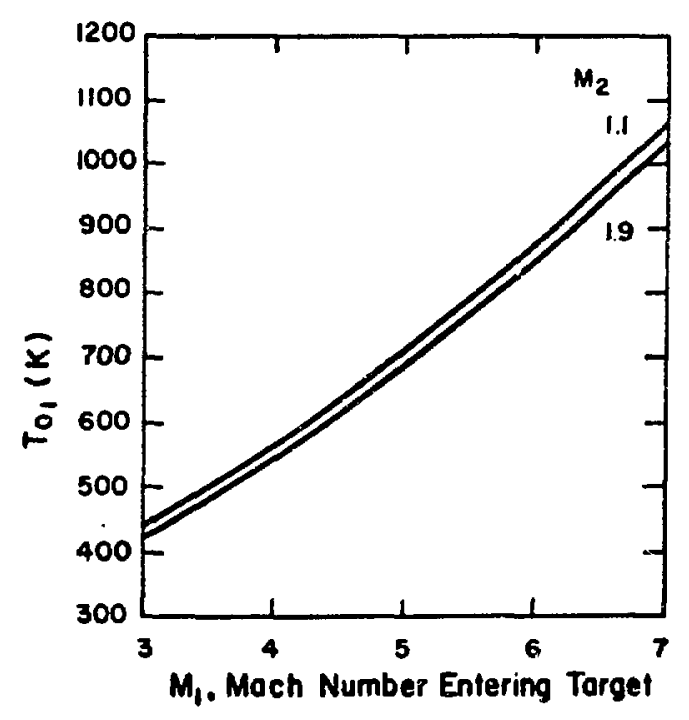

Fig. 10. Target inlet stagnation temperature.

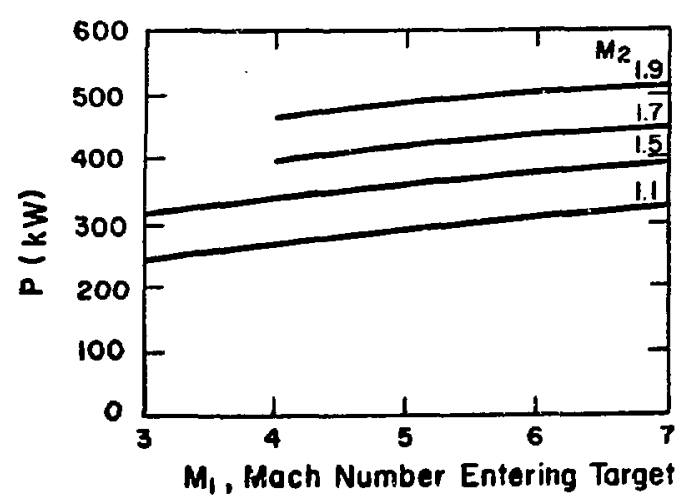

Fig. 11. Ideal pump work.

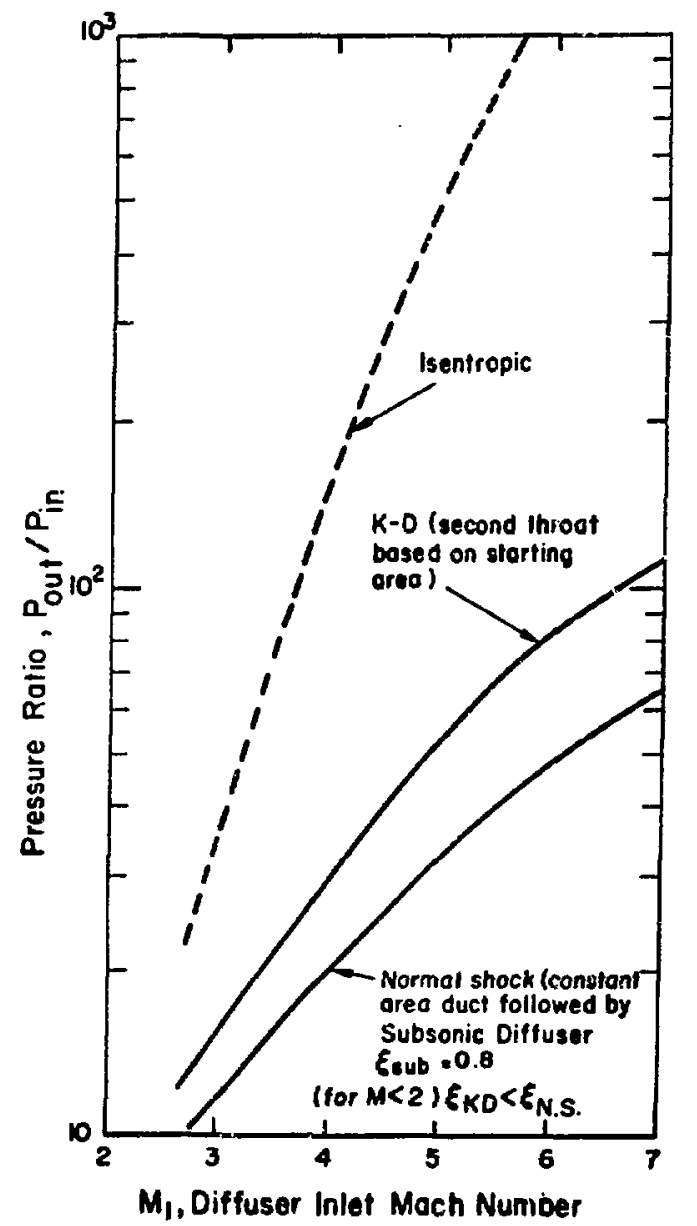

Fig. 12. Compression ratios for various conditions of diffusion. 


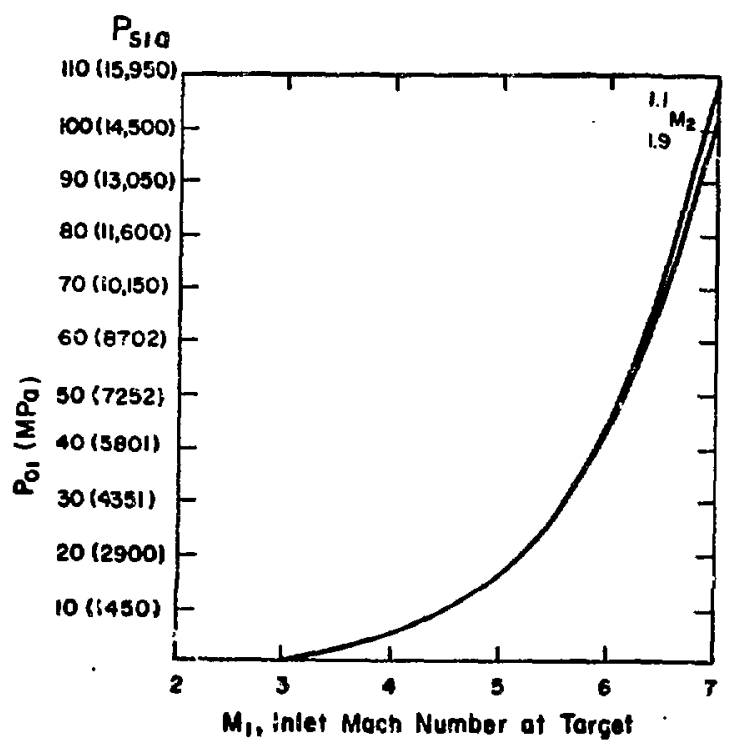

Fig. 13. Target stagnation pressure.

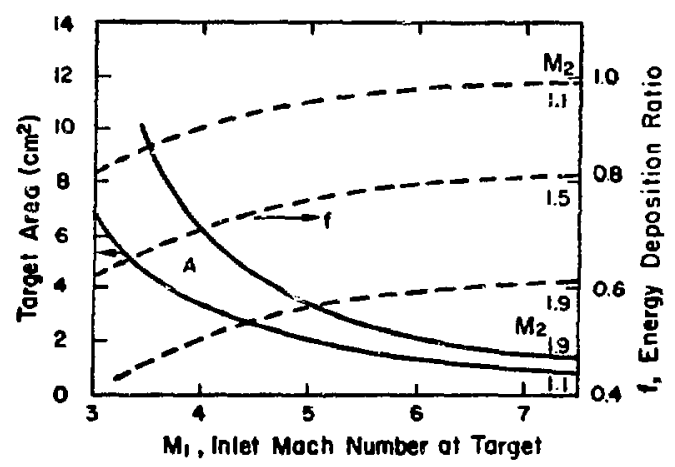

Fig. 14. Target area and energy deposition ratio.

$M_{2}=1.7$, for exampl,$E=0.69$ and $A_{1}=1.86 \mathrm{~cm}^{2}$. Table I summarizes a set of reference conditions for the loop. For the example conditions, the $D_{2}$ stagnation temperature entering the target area is $.450 \mathrm{~K}$ $\left(1070^{\circ} \mathrm{F}\right.$ ) (Fig. Jo) and the id.al pump work is 43. kl. Target exit stagnation temperature is about $1575 \mathrm{~K}$ $\left(2000^{\circ} \mathrm{F}\right.$ ) (Fig. 15); water flow in the heat exchanger is about $3.75 \mathrm{~kg} / \mathrm{s}$ (Fig. 16); and the $D_{2}$ fluw rate is $0.08 \mathrm{~kg} / \mathrm{s}$ (Fig. 17).

For the figures just presented, $D_{2}$ gas density in the target area was held fixed at $0.13 \mathrm{~kg} / \mathrm{m}^{3}$ $\left(2 \times 10^{19}\right.$ molecules per $\left.\mathrm{cm}^{3}\right)$. Figures 18 and 19 show how system variables aze affected by changes in gas density $f_{1: r}$ constant $M_{2}$. With fixed target

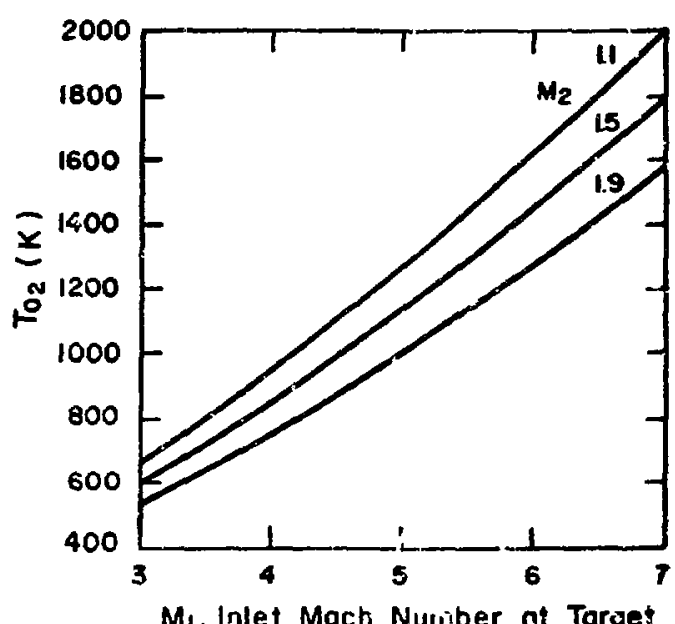

Fiy. 15. Stagnation temperatur $\geq$ at target.

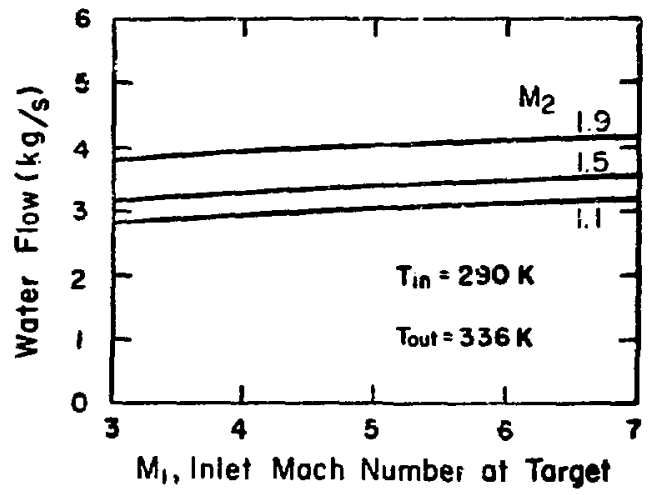

Fig. 16. water flow.

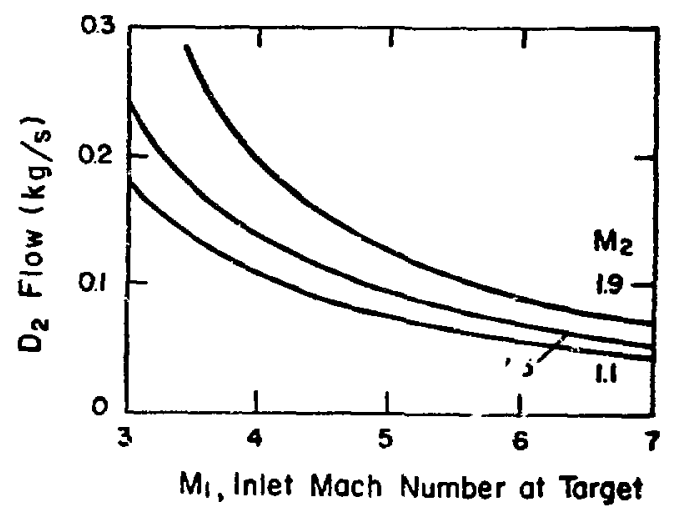

Fig. 17. Deuterium flow. 
TABLE I

RI. ERENCE CONDITIONS FOK $D_{2}$ LOOP

\begin{tabular}{|c|c|c|c|c|}
\hline$M_{1}$ & Mach number entering target & 6 & $v_{4}$ & $\begin{array}{l}\text { Velocity exiting subsonic } 200 \mathrm{~m} / \mathrm{s} \\
\text { diffuser }\end{array}$ \\
\hline $\begin{array}{l}M_{2} \\
0\end{array}$ & $\begin{array}{l}\text { Mach number leaving target } \\
\text { Gas density entering target }\end{array}$ & $0.13 \mathrm{~kg} / \mathrm{m}^{3}$ & $\mathrm{~d}_{4}$ & $\begin{array}{l}\text { Diameter of subsonic diffuser } \\
\text { exit and heat exchanger i.d. }\end{array}$ \\
\hline A! & Target flow area & $\begin{array}{l}\text { molecules } / \mathrm{cm}^{3} \mathrm{~J} \\
1.86 \times 10^{-4} \mathrm{~m}^{2}\end{array}$ & $A_{4}$ & $\begin{array}{l}\text { Flow area of subsonic cif- } \\
\text { fuser exit and heat exchanger }\end{array}$ \\
\hline 9 & Ion beam energy & $300 \mathrm{~kW}$ & $L_{4}-5$ & Length of heat exchanger \\
\hline$v_{1}$ & $D_{2}$ velocity estering target & $3302 \mathrm{~m} / \mathrm{s}$ & LMTD & Heat exchanger log-mean \\
\hline$x_{0 !}$ & $\begin{array}{l}\text { Staynation temperature enter- } \\
\text { ing target }\end{array}$ & $858 \mathrm{~K}$ & & $\begin{array}{l}\text { temperature difference } \\
\text { water flow rate }\end{array}$ \\
\hline $\mathbf{T}_{1}$ & $\begin{array}{l}\text { Static temperature entering } \\
\text { target }\end{array}$ & $104.5 \mathrm{~K}$ & $T_{\text {in }} / T_{\text {out }}$ & $\begin{array}{l}\text { Water inlet and outlet. } \\
\text { temperature }\end{array}$ \\
\hline Po & Stagnation pressure at targ̣et & $\begin{array}{c}\text { 44. } 7 \text { MPa } \\
(6440 . \text { Psia) }\end{array}$ & $\operatorname{Re}_{w}$ & Water Reynolds number \\
\hline$P_{1}$ & Static pressure at target & $28.1 \mathrm{iPa}$ & $h_{w}$ & $\begin{array}{l}\text { Average water side heat } \\
\text { transfer coefficient }\end{array}$ \\
\hline$\dot{\mathrm{m}}$ & $D_{2}$ mass flow & $0.08 \mathrm{~kg} / \mathrm{s}$ & $A_{w}$ & Water side flow area \\
\hline$f$ & $\begin{array}{l}\text { tof } \frac{1}{2} \text { in } v_{l}^{2} \text { energy deposition } \\
\text { ratio }\end{array}$ & 0.69 & $v_{w}$ & Water velocity \\
\hline$T_{02}$ & $\begin{array}{l}\text { Staqnation temperature leav- } \\
2 \pi g \text { target }\end{array}$ & $1375 \mathrm{~K}$ & d: & $\begin{array}{l}\text { o.d. of inner concentric } \\
\text { tube in heat exchanger } \\
\text { (water passage i.d.l }\end{array}$ \\
\hline $\mathrm{T}_{2}$ & $\begin{array}{l}\text { Static temperature leaving } \\
\text { target }\end{array}$ & $871 \mathrm{~K}$ & $d_{3}$ & $\begin{array}{l}\text { i.d. of outer concentric } \\
\text { tube in heat exchanger }\end{array}$ \\
\hline $\mathbf{P}_{z}$ & Static pressire leavaru earqut & $286.7 \mathrm{kPa}$ & & (water passage o.d.) \\
\hline$v_{2}$ & $\begin{array}{l}\text { Target exit velocity } \\
\text { Target exit density }\end{array}$ & $\begin{array}{l}2701 \mathrm{~m} / \mathrm{s} \\
0.16 \mathrm{~kg} / \mathrm{m}^{3}\end{array}$ & $\overline{\mathrm{T}}$ & $\begin{array}{l}\text { Average heat exchanger } \\
\text { wall temperature }\end{array}$ \\
\hline$P_{2} / P_{:}$ & $\begin{array}{l}\text { rtatic pressure ratio at } \\
\text { target }\end{array}$ & 10.2 & $T_{\max }$ & $\begin{array}{l}\text { Maximum heat exchanger } \\
\text { wail temperature }\end{array}$ \\
\hline$\dot{\Delta}_{2}$ & $\begin{array}{l}\text { Diameter of supersonic dif } \\
\text { fuser (and target duct) }\end{array}$ & $1.54 \times 10^{-2} \mathrm{~m}$ & $u$ & $\begin{array}{l}\text { Overall heat transfer coef- } 1026 \mathrm{w} /\left(\mathrm{m}^{2} \cdot \mathrm{K}\right) \\
\text { ficient for heat exchanger }\end{array}$ \\
\hline L.?-3 & $\begin{array}{l}\text {.ength of supersonic diffuser } \\
\text { section (assuming } 100 \mathrm{~kW} \text { if }\end{array}$ & $-1.2 \mathrm{~m}$ & $P_{w}$ & $\begin{array}{l}\text { Suggested water pressure } \\
\left.\text { (P }{ }_{\text {sat }} \text { at } T_{\text {max }}\right)\end{array}$ \\
\hline & $\begin{array}{l}\text { cooling for control ox wall } \\
\text { temperatures }\end{array}$ & & $\mathrm{T}_{5}$ & $\begin{array}{l}\text { Douterium exit temperature } \\
\text { from heat exchanger (speci- }\end{array}$ \\
\hline $\operatorname{Re}_{3}$ & $\begin{array}{l}\text { Reynolds number in supersonic } \\
\text { dif fuser }\end{array}$ & $2.77 \times 10^{5}$ & $\operatorname{Re}_{6} \ldots 5$ & $\begin{array}{l}\text { fied for design) } \\
\text { Average deuterium Reynolas }\end{array}$ \\
\hline$M_{3}$ & $\begin{array}{l}\text { Mach number exiting supersonic } \\
\text { diffiser }\end{array}$ & 0.6 & $h_{4}-5$ & $\begin{array}{l}\text { number in heat excilanger } \\
\text { Average deuterium hea: }\end{array}$ \\
\hline$P_{3}$ & $\begin{array}{l}\text { Static pressure exiting super- } \\
\text { sonic diffuser }\end{array}$ & $0.91 \mathrm{Mra}$ & $P_{5}$ & $\begin{array}{l}\text { transfer coefficient } \\
\text { Exit static pressure from } \\
\text { heat exchanger }\end{array}$ \\
\hline $\mathrm{T}_{03}$ & $\begin{array}{l}\text { Stagnation temperature exi- } \\
\text { ing supersonic diffuser }\end{array}$ & $1202 \mathrm{~K}$ & $P_{4-5}$ & $\begin{array}{l}\text { Heat exchanger pressure } \\
\text { drop }\end{array}$ \\
\hline $2+3-4$ & (assuming $3^{\circ}$ half-angle) & 0.1 & $P$ & $\begin{array}{l}\text { Ideal isentropic compres- } \\
\text { sor work. }\end{array}$ \\
\hline 14 & $\begin{array}{l}\text { Mach number exiting subson.c } \\
\text { diffuser }\end{array}$ & 0.1 & $\mathrm{P}_{01} / \mathrm{P}_{5}$ & Cycle compression ratio \\
\hline$P_{4}$ & $\begin{array}{l}\text { Static pressure exiting sub- } \\
\text { sonic diffuser }\end{array}$ & $1.16 \mathrm{MFa}$ & $T_{f_{1}}$ & $\begin{array}{l}\text { Adiabatic compressor exit } \\
\text { temperature }\end{array}$ \\
\hline
\end{tabular}

a Conditrons at Station 2 (target exit) are based on the Rayleigh line, with no shocks in the target area. This gives conservatively low pressure recovery. 


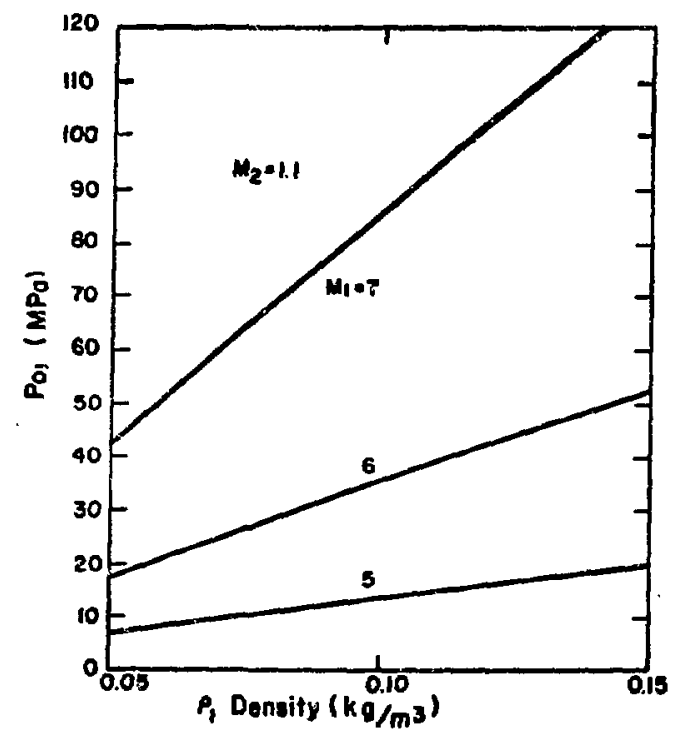

Fig. 18. Target stagnation pressure versus deuterium density, $M_{2}=1.1$.

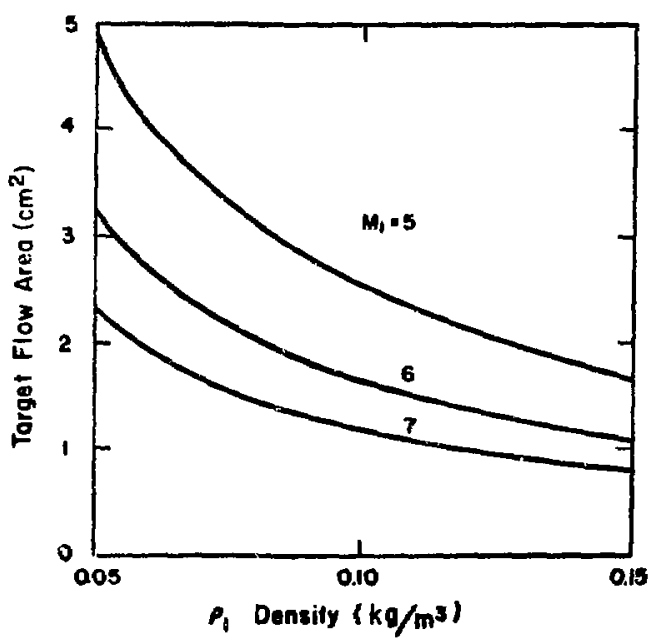

Fig. 19. Target area versus deuterium density.

inlet and exit Mach number, $\Delta Q$ fixed, and target gas density varying; the ideal pump work, energy depcsition fraction, target inlet and exit stagnation temperature, and $D_{2}$ flow are all constant. The system pressure levels and target flow area are the only significant parameters that vary.

\section{Heat Exchanger}

\section{Diffuser Section}

One of the purposes of all the preceding was to arrive at reasonable and consistent parameters $\left(D_{2}\right.$ flow, inlet temperature and pressure) for the heat exchanger design. The diffuser sections were sized such that the inlet Mach number to the heat exchanger was fixed at 0.1 . The diffuser walls were assumed adiabatic, although a practical design may include some cooling to control material tenperatures. significant cooling of the $D_{2}$ gas in the diffuser section introduces some problems to be discussed later. The length ${ }^{*}$ of the supersonic section of an adiabatic aiffuser is about 5 to 10 diameters for $y_{2}$ between 1 and 2 (Ref. 6). The diffuser dianeter is the same as the target area diameter. The lengtt. of the subsonic diffuser section, based on a $3^{\circ}$ half-angle with the exit Mach number equal to 0.1 . ranged from 0.15 to 0.5 meter.

2. Heat Exchanger Dimensions ard Performance

$F$ igures 20 and 21 show heat exchanger dimensions as a function of target area inlec and exit Mach numbers. The heat exchanger was sized to remove the tatal of pumping power and beam energy (300 kW) not accounting for the assumed ( $\sim 258)$ cooling of the gas during and after compression. For the assumed $M_{1}=6$ and $M_{2}=1.7$, the heat exchanger is about $23 \mathrm{~m}$ long $\times 0.035 \mathrm{~m}(1.4 \mathrm{in}$.) i.d. on the gas side and $0.074 \mathrm{~m}(2.9 \mathrm{in.})$ o.d. on the water side (inside diameter of outer concentric pipe). The static pressure $105 \mathrm{~s}$ is about $28 \mathrm{kPa}$ (4 psi),

* This is the minimum length, corresponding to the length of the "pseudo shock" (see p. 13).

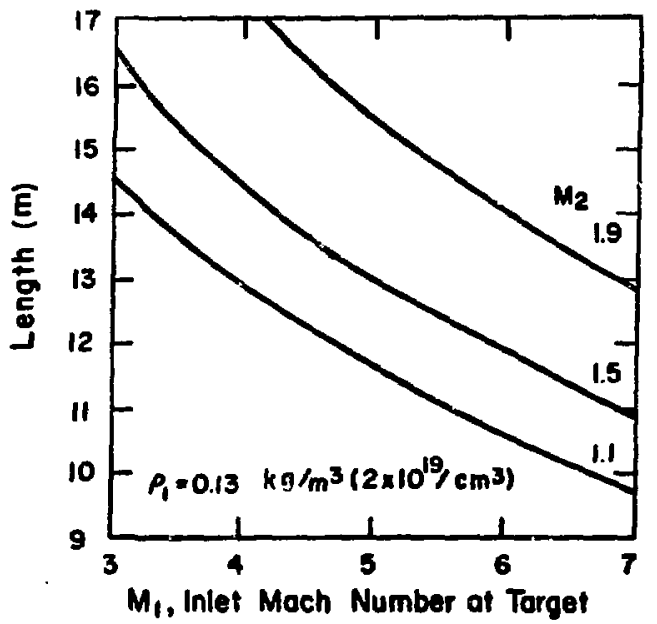

Fig. 20, Heat exchanger length. 


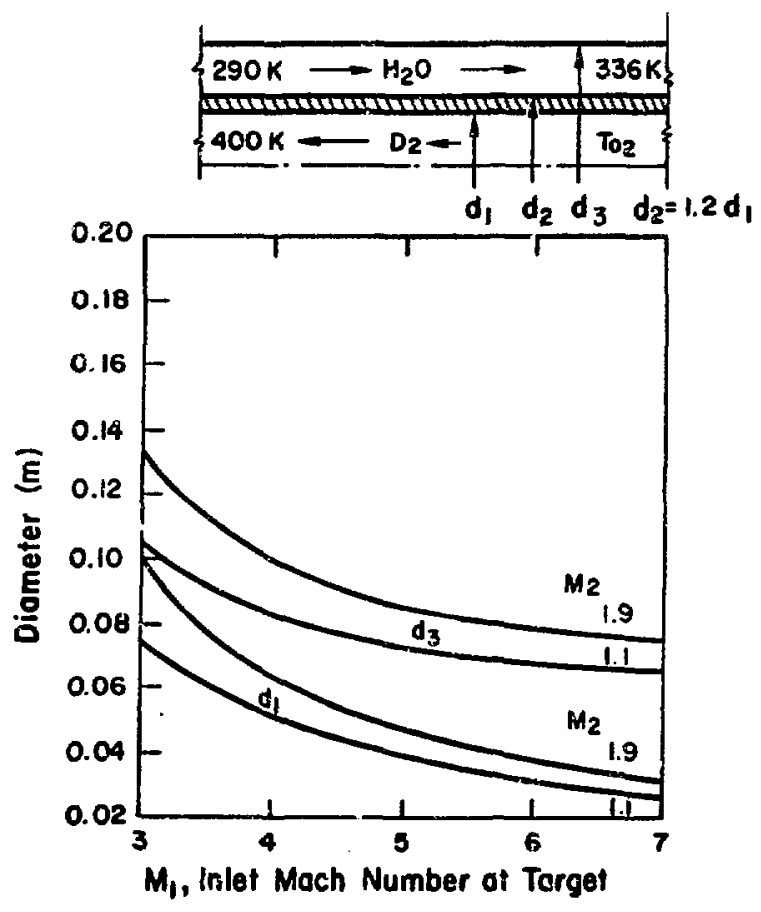

Fig. 21. Heat exchanger dianecer.

Fig. 22, and the exit pressure is $1.12 \mathrm{MP}$ (162 psia). The exit pressure is not significantly affected by changes in $M_{2}$ (ard $f$ ), $F i g .23$. The effect of target gas density on the heat exchanger desigr is shown in Figs. 24 through 27. The design and performance are not very sensitive and changes in target operating density can probably be compensated for by adjustments in water flow, water inlet temperature and/or $\mathrm{D}_{2}$ exit temperacure.

3. Consideration of Boiling versus Nonboiling Design

Design of the heat exchanger with the assumption of no boiling is conservative from the standpoint that surges in the $\mathrm{D}_{2}$ flow, inlet temperature, or water pressure, would not result in film boiling or burnout with possible damage. Figures 28 and 29 show, respectively, the maximum wall temperature and heat flux, $q^{\prime \prime}$ (at $D_{2}$ inlet). For $M_{1}=6$ and $M_{2}=1.7$, the maximum wall temperature is $520 \mathrm{~K}$ $\left(\$ 76^{\circ} \mathrm{F}\right)$. This is well within the capability of chrome-nickel alloy steels. If the water pressure is set to correspond to the saturation pressure at the maximum wall temperature (about $3.8 \mathrm{MPo}$ or 550 psia in this case), any reasonable increase in
$D_{2}$ exit temperature, flow rate, or local film coefficient will only cause local nucleate boiling on the water side. The heat exchenger could have been made shorter--thus cheapex--by designing it for nucleate boiling under normal operation. Aside from the reduced safety margis, the gas side would have to be internally finned to take full advantage of the high boiling heat transfer coefficient--chus tending to offset some of the cost advantage. The fins on the

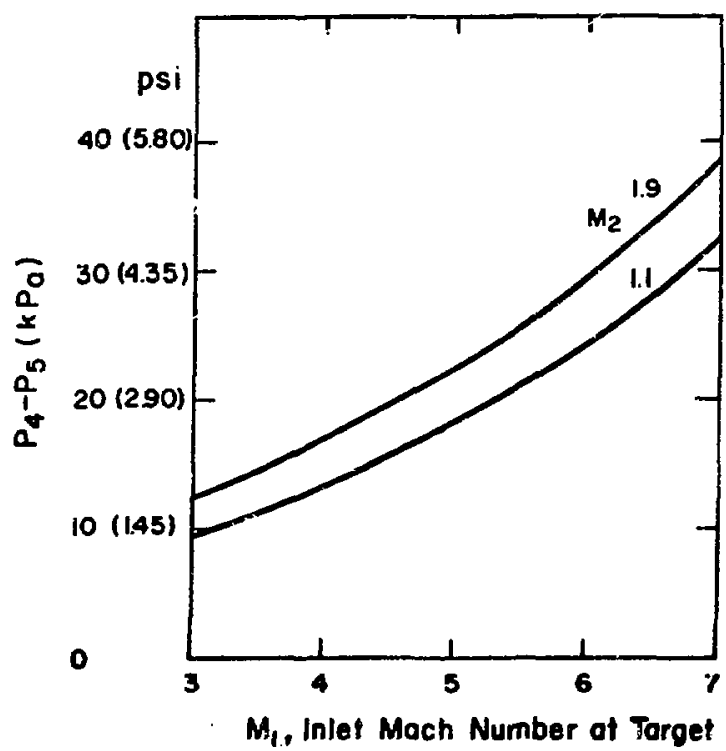

Fig. 22. Heat exchanger static pressure loss.

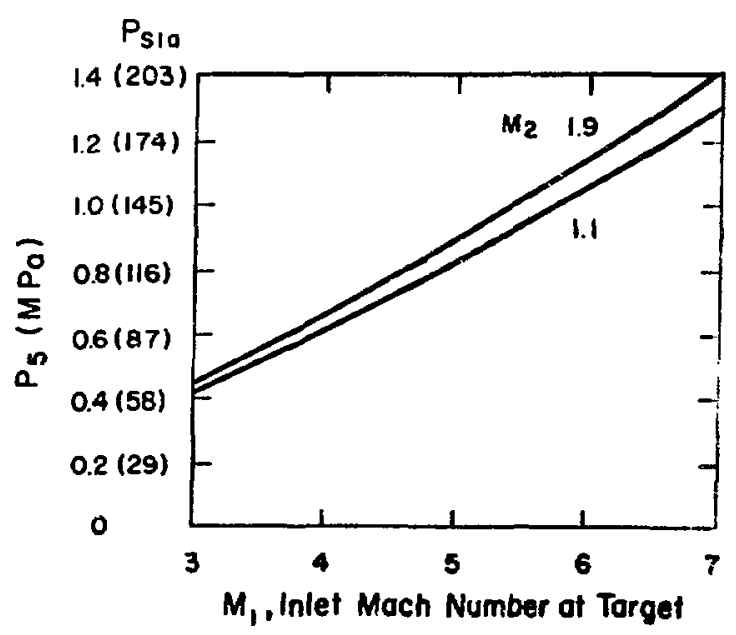

Fig. 23. Heat exchanger exit pressure. 


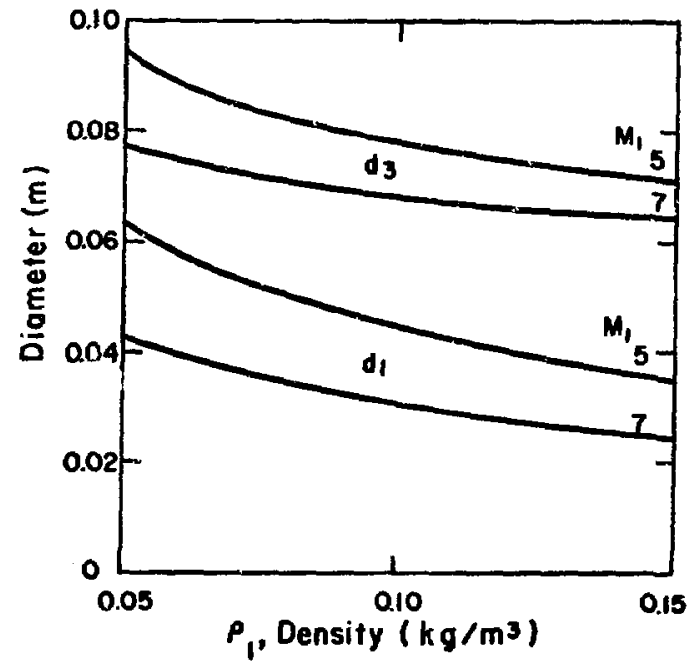

Fig. 24. Effect of target yas density on heat exchanger diameter.

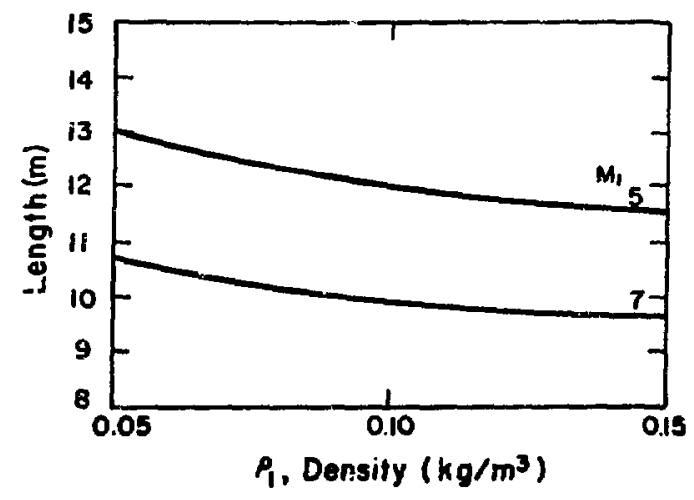

Fig. 25. Effect of target gas density on heat exchanger length.

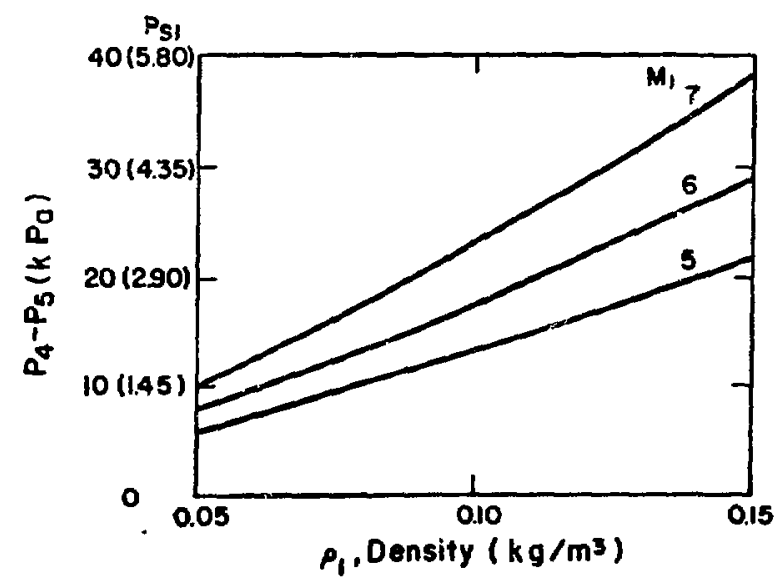

Fig. 26. Effect of target gas density on heat exchanger pressure loss.

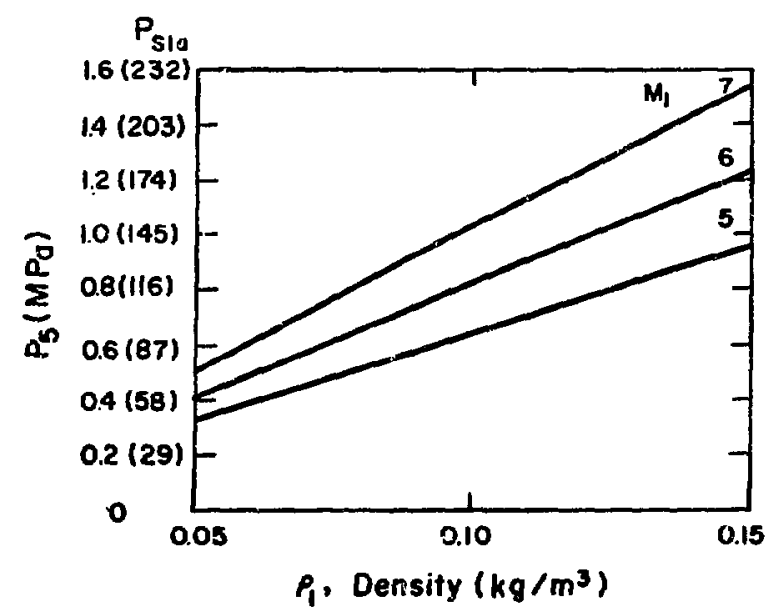

Fig. 27. Effect of target gas density on heat exchanger exit pressure.

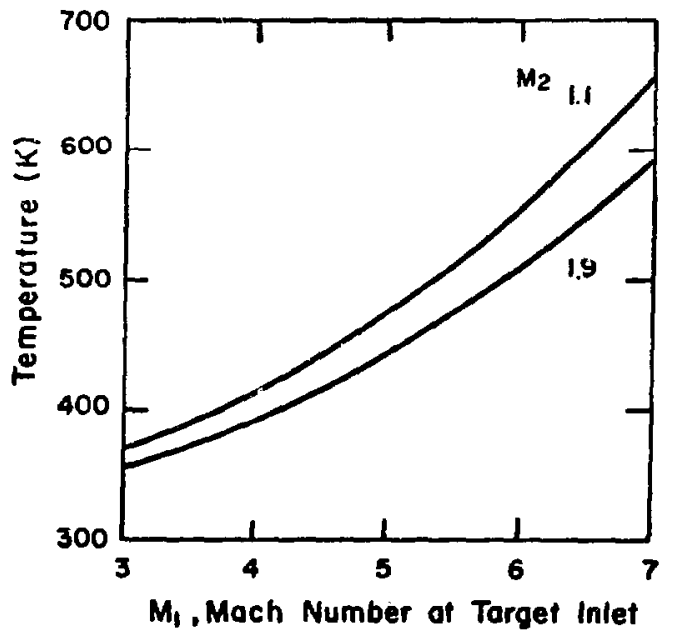

Fiq. 28. Maximum heat exchanger wall temperature (assumes no boiling). 


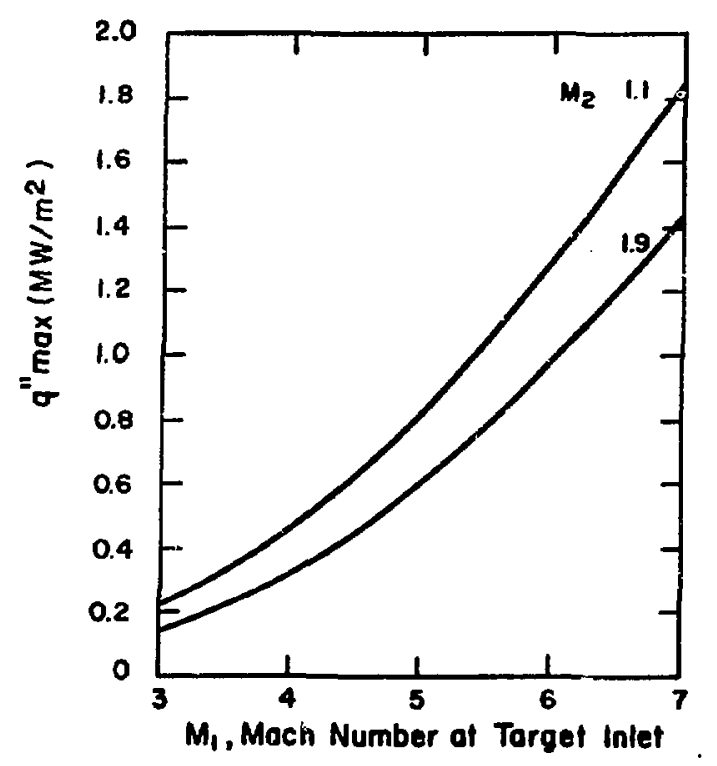

Fig. 29. Maximur local heat flux in heat exchanger.

gas side would be needed because only about 158 of the overall heat transfer resistance is on the water side--thus the length reduction would only be significant if both the water and gas side heat transfer were improved. Adding the fins (with a length reduction) will cause a net increase in the static pressure loss (see the Appendix) which, coupled with the preceding, argues strongly for the conservative nonboiling design.

\section{Cooling Diffuser Sections}

Diffu er sections will probably reguire cooling to maintain the walls within acceptable temperature limits. Uncooled walls would reach the gas stagnation temperature (Fig. 15) and at the higher Mach numbers, would require refractory metals. Inconel 718 would be an excellent choice for temperatures up to $1000 \mathrm{~K}\left(1350^{\circ} \mathrm{F}\right)$, but cooling the walls would likely be a more practical and less expensive alternative. In the absence of shock wave:s (Rayleigh flow) cooling a supersonic flow increases the Mach number and there is an upper limit to the amount of cooling that can take place (Fig. 30). The actual character of the shock structure in the duct will be oblique rather than nornal. The shuck structure has been termed a "pseudo shock" by crocco ${ }^{8}$ and the following summary is a quotation.

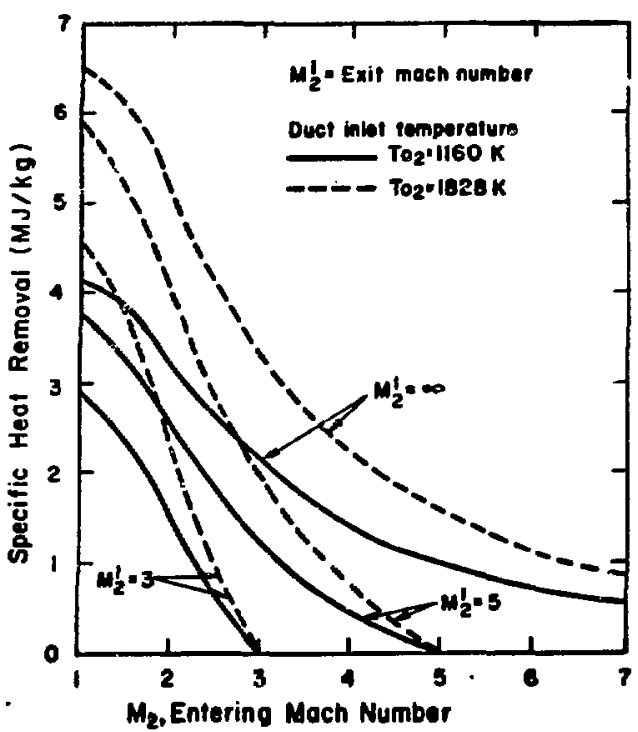

Eicj. 31). Maximum cooling of frictionless supersonic flow in constant area duct without shock.

"Only for low supersonic velocities and thin boundary layers is a quasi-normal shock possible in a duct. Otherwise, a more complicated, non-onedimensional pattern is produced, which, for sufficiently high Mach numbers becones multiple. Arove a certain boundary layer thickness this multiple pattern contains only oblique shocks crossing the center of the duct and reflected back and forth in the central supersonic region of flow, while the region adjacent to the wall is adjusted gradually to the pressure increase. This adjustment is produced by strong exchanges of momentum due to the high turbulence generated in these regions ... the corresponding frictional effects are small and therefore the relations between the initial supersonic conditions and the final subsonic conditions are very close to those derived on assumptions that are exactly true only for a normal shock."

When the pressure gradient that the boundary layer must adjust to is high enough (about 2) separation occurs, with a recirculation "bubble" adjacent tc the wall, bounded by a shear layer. The structure of these cavities is dominated by the interplay of constraints at the separation and recompression points, with matching of the inviscid and viscous flow along the dividing streamline. 
There is no unifying theory and the existing models are insufficiently refined to explain many of the observable phenomena. ${ }^{9}$ There is no reliable framework for dealing with heat transfer. Heat transfer problems are still mainly a question of judicious interpretation of experimental data.

In spite of the pitfalls, we will try to place some estimate on the effects of cooling the supersonic flow. Reference 10 suggests that the local heat transfer coefficient (for turbulent separated flow over a flat plate at $M=6$ ) is a factor of 2 greater than the corresponding flow with no separation. A large body of evidence ${ }^{6,7,8}$ concludes that (for adiabatic flow, at least) the static pressure rise in a duct with supersonic inlet and subsonic exit is close to that of a normal shock. We will assume that the heat transfer coefficient is equal to twice that with no shocks (and no boundary separation). The flow is accelerated from $M_{2}=1.7$ to $M_{3}^{\prime}$ along the Rayleigh line while cooling and subsequently a normal shock (series of rowido-shocks) reduces $M_{3}^{\prime}$ to $M_{3}$. The actual be'savior will involve simultaneous cooling with a series of oblique shecks all along the tube, rather than sequentially as described. Figures 31 through 33 show $\mathrm{T}_{03}, \mathrm{P}_{3} / \mathrm{P}_{2}$. and $M \xi$ versus the heat removal rate, $Q$. For these conditions, the length of the cuoleo section is approximately 1 meter per $100 \mathrm{~kW}$ of cooling. the final subsonic Mach number is between 0.4 and 0.6 . and the maximum duct wall temperature is atout $1170 \mathrm{~K}^{*}$.

The length of the subsonic heat exchanger is not greatly reduced by the additionad cooling in the diffuser section. The reason is that the majority of the length is devored to cooling the gas over the bottom end of the temperature range. The length needed for removing the first $100 \mathrm{~kW}$ is about $1 / 16$ the length frar removing the last $100 \mathrm{kw}$.

In this study no attemge was made to trade ust the heat exchanger's carsital cost with eperarstw costs as was done in Ref. 1. This is beaus: (1) the cest of the heas exchanger is a very sim th

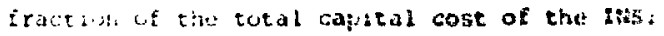

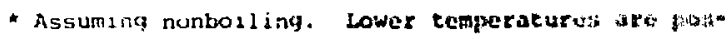
sibl.. with selection of water pressture to thaw boillas. Insulating the fiffuser wall with. for i xamplice concentric tubes of thin shere cats that

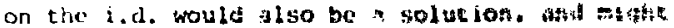
be necessary.

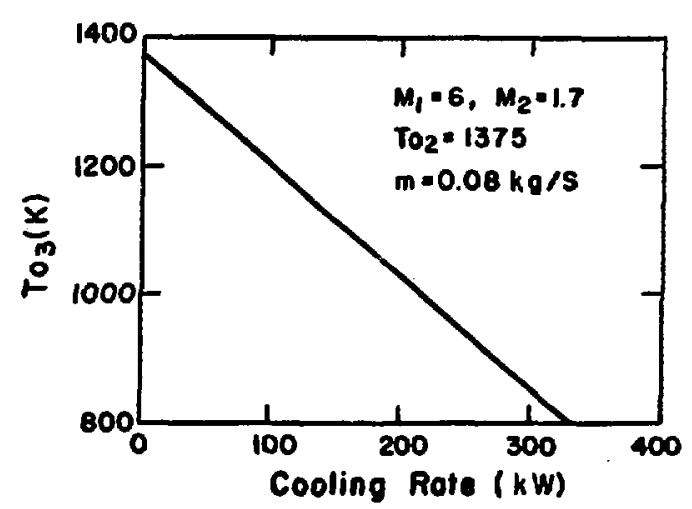

Fig. 31. Cooled supersonic diffuser exit temperature.

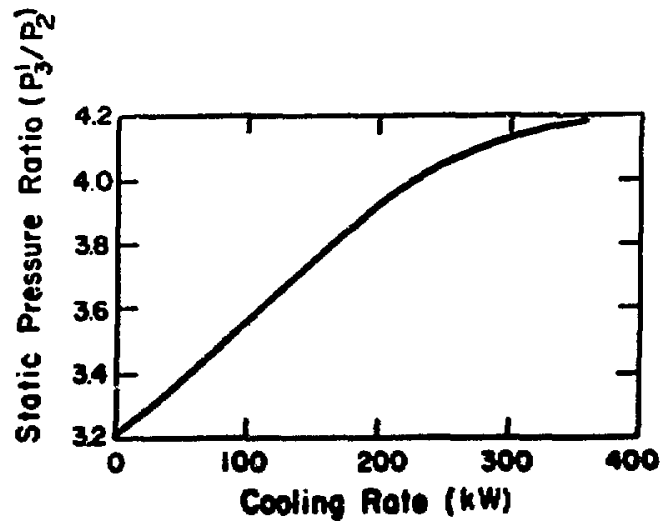

Fig. 32. Seacic press bre racjo.

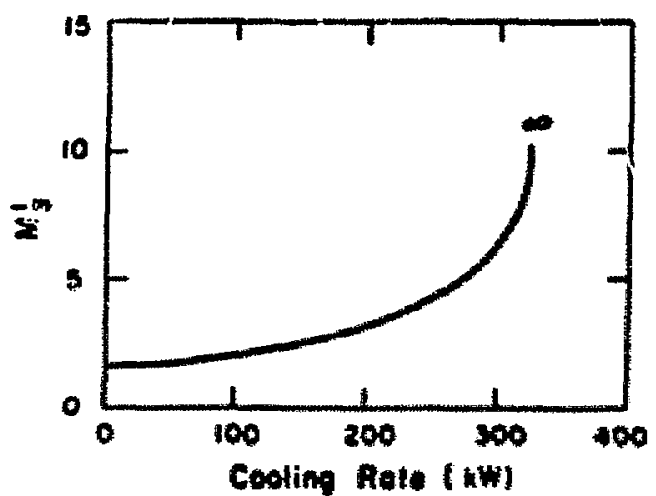

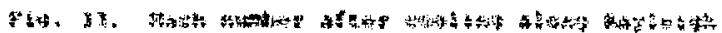

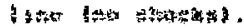


(2) the conditions inder which the heat, exchanger must operate are not now well determined and may fluctuate with varying experimertal conditions and or design changes in the rest of the INS; and (3) the pressure loss in the heat exchanger is a negligible contribution to the overall system pressure ratio and operating cost. There was an attempt to maintain the heat exchanger exit pressure as high as possible, to maintein temperature levels within the acceptable range for common metals, to keep the design simple to fabricate, and to have sufficient design margin to accomnodate changes in upstream conditions or transients.

D. Recommendations and Conclusions

Feasibility of the INS, as fresently envisioned, depends heavily on the supersonic nozzle and target area's performance. Surstions that should be resolved by detailed dnalysis and exper. iments include:

- Amount of deuteriun luakage into the ion beam tube.

- Choking limits for deuterium flow based on ion beam pwer, nozzle-duct geometry, and flow condinions.

- Pressuro "ucovery in target and diffuser.

- Electrol-ion collision rate versus D-T reaction roto and inpuct on this above.

In particular, for the final dosign of the

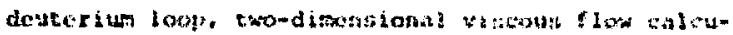

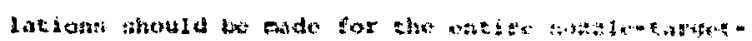

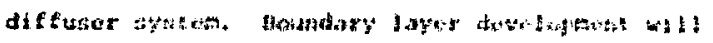

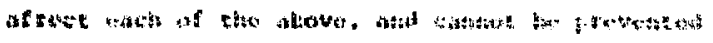

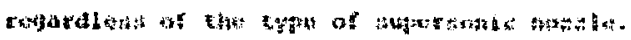

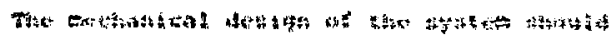
cothat

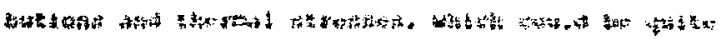
Hexter.

然地

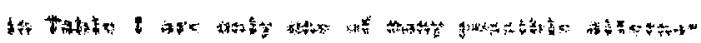

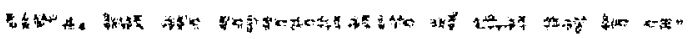

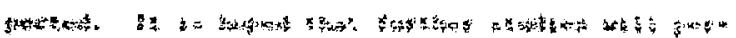

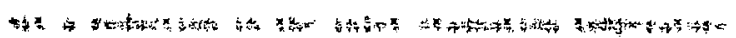

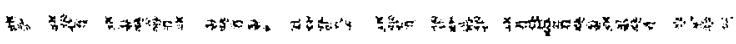

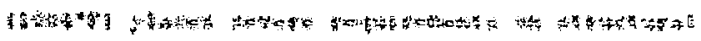

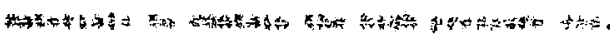

\section{REFERENCES}

1. C. R. Emigh, J. E. Brolley, Jr., and M. C. Cline, "A Proposal for a 14-MeV Intense Neutron Source at Los Alamos, New Mexico," LA-5191-P, May 1973.

2. 3. Zierep, "Theory of Flows in Compressible Media with Heat Addition," AGARD-AG-191. NATO Advisory Group for Aerospace Research and Develofment.

3. Samuel Glasstone and Ralph H. Lovberg, Controlled Thermonuclear Reactions (Van Nostrand 1960).

4. Asher H. Shapiro, The Dynamics and Thermodynanics of Compressible fluid Flow, Vols. I and II (Ronald Press 1354).

5. Wallace D. Hayes, "Theory of Gasdynamic Discortinuities," Fundamentals of Gas Dynamics, Vol. III (Princeton University Press 1958), p. 419.

6. E. P. Neumann and E. Lustwerk, "Supersonic Dilfusers for wind Tunnels," Journal of Applifs Mechanics, June 1949, pp. 195-202.

\%. P. J. Waltrup and F. S. Billig. "Structurc of Shock Waves in Cylindrical Ducts," AIAA Journal, Vol. II, No. 10. p. 1404 (October 1973).

8. Luigi Crocco. "One-Dumensional Treatment of sis Dynamics." rundamencals of Gas Dymamies. Vol. II (Princeton University Press 1956).

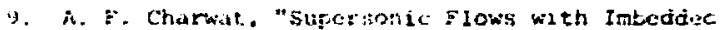
Stparated focir...." Advances $2 n$ Heat Transfer,

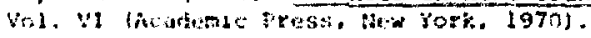

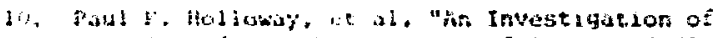

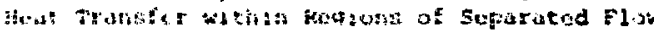

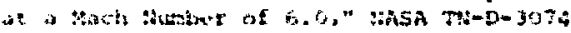

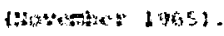

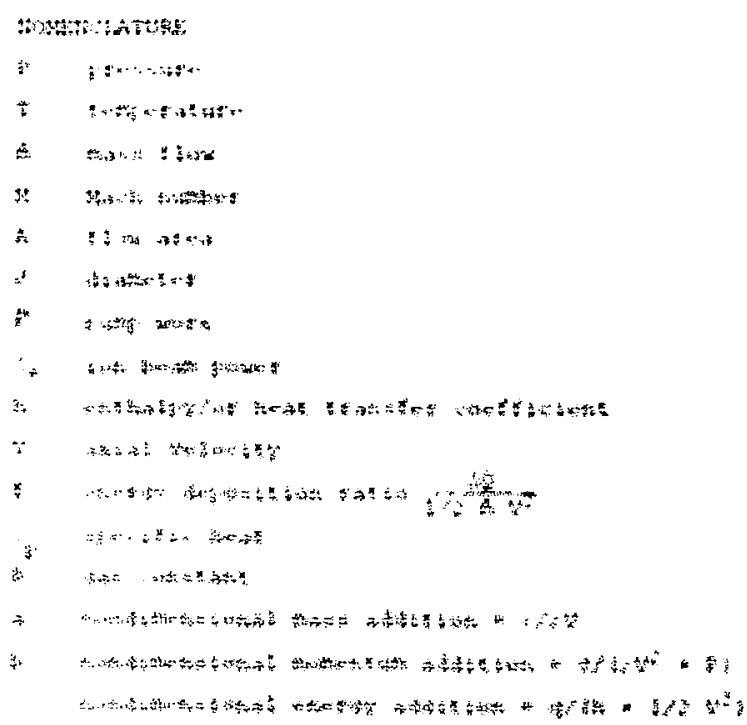


q heat addition per unit mass

$u, u$ radial velocity

p density

E mass addition per unit area per unit time

o momentum addition per unit area per unit time
$Y$ Subscripts

0

1,2, etc. station defined by Fig. 1 Superscript ratio of specific heats

stagnation condition

signifies sonic condition.

APPENDIX

USE OF INTERNAL FINS IN HEAT EXCHANGER

N fins of arbitrary shape.

Flow area $=\mathrm{A}$, Perimeter $=\mathrm{s}$.

Surface area $=s d x$.

$\eta=f$ in effectiveness $=\frac{q\left(\operatorname{actual} T_{f i n}\right)}{q\left(T_{f_{\text {in }}}=T_{w}\right)}<1$.

The energy equation is:

$A \rho v c_{p} d T_{0}=\eta h S d x\left(T_{w}-T_{a w}\right)$.

Assume adiabatic wall temperature, $\mathbf{T}_{\text {aw' }}$ equals stagnation temperature, $\mathrm{T}_{0}$. This is equivalent to a recovery factor $r_{c}=1$. The actual value of $r_{c}$ is about equal to $\sqrt{\mathrm{P}_{\mathrm{r}}}$.

Then,

$\frac{d T_{0}}{T_{w}-T_{0}}=\frac{h s d x}{h \rho V C_{p}} \eta$

Ising the Keynolds analogy (the error is small,

$\sim 8$, for $P_{r}$ close to 1 )

$\frac{h}{\rho V c_{p}}=\frac{f}{2}$

Then,

$\frac{d T_{0}}{T_{w}-T_{0}}=\frac{\eta E S}{2 A} d x$

and

$\frac{7}{2}\left[\frac{s}{A}\left(x_{2}-x_{1}\right)\right]=\ln \frac{T_{w}-T_{01}}{T_{W}-T_{02}}$.

If $r_{c} f 1$. constants would enter on the right side. The quancity in brackets on the left is the friction cocfeicient. $c_{f^{*}}$ Approximation to the pressuro drop equation:

$$
\begin{aligned}
& -d p=\frac{G^{2} \bar{v}}{2} d C_{f}+G^{2} d v . \\
& d C_{f}=\frac{f}{A} d x \\
& P_{1}-P_{2}-G^{2}\left[1 / 2 \bar{v} C_{f}+v_{2}-v_{1}\right] \\
& \mathbf{v}=\frac{\mathrm{RT}}{\mathrm{R}} \\
& \mathrm{P}_{1}-\mathrm{P}_{2}=\mathrm{G}^{2} \mathrm{R}\left[\frac{\mathrm{C}_{\epsilon}}{4}\left(\frac{\mathrm{P}_{1}}{\mathrm{P}_{1}}+\frac{\mathrm{T}_{2}}{\mathrm{P}_{2}}\right)+\frac{\mathrm{T}_{2}}{\mathrm{P}_{2}}-\frac{\mathrm{T}_{1}}{\mathrm{P}_{1}}\right] \\
& P_{2}{ }^{2}-P_{2}\left[P_{1}-\frac{G^{2} R T_{1}}{P_{1}}\left(\frac{C_{f}}{4}-1\right)\right]+G^{2} R^{\prime} \Gamma_{2}\left(\frac{C_{f}}{4}+1\right)=0 \\
& \gamma M=\frac{V_{l}^{2}}{R_{1}}=\frac{G^{2} R_{1}}{P_{1}^{2}} \\
& \mathrm{P}_{2}{ }^{2}-\mathrm{P}_{1} \mathrm{BP}_{2}+\mathrm{P}_{1}{ }^{2} \mathrm{E}=0 .
\end{aligned}
$$

Where:

$$
\begin{aligned}
& B=1-\gamma M_{1}^{2}\left(C_{f^{\prime}} / 4-1\right\} \\
& E=\gamma M_{1}^{2} \frac{T_{2}}{T_{1}}\left(C_{f^{\prime}} / 4+1\right)
\end{aligned}
$$

$\frac{P_{2}}{P_{1}}=1 / 2\left[B+\sqrt{B^{2}-4 E}\right]$.

All except $c_{f}$ in the above are fixed by flow conditions and not geometry. From the energy equation:

$C_{E}=\frac{2}{\eta} \ln \frac{T_{W}-T_{01}}{T_{W}-T_{02}}$

The value of $c_{f}$ is $f i x e d$ by the energy equation. and is increased by the fin effectiveness < 1 . If $\eta=1$, then length can be reduced by adding fins, and the pressure drop remains constant. Since $\eta$ is 
never 1 for actual fins, we cossclude that zading fins hurts $\Delta \mathrm{P}$.

in practice, fins are usually used where:

1. Heat exchanger weight and/or volume are of extreme importance (aircraft and. spacecraft).

2. Pumping power on the gas side is "free" or of smaller importance lautomotive radiators, industrial applications, air corsitioners).
3. The gas $h$ is $-1 / 100$ to $1 / 50$ the 1 iquid $h$ (air to water). In this case, $D_{2}$ is a very good heat exchange medium and the gas $h$ is about $1 / 4$ the nonboiling water $h$.

Since minimum $\Delta P$ is of prime importance for this application, internal fins on the gas side are not desirable. 